\title{
Responsabilidad jurídica de las instituciones educativas frente al bullying
}

\author{
Nubia Marrugo Nuñez \\ nubia.marrugo46@uac.edu.co \\ Universidad Autónoma del Caribe \\ Helena del Carmen Morales Ortega \\ helena.morales@uac.edu.co \\ Universidad Autónoma del Caribe
}

\section{Resumen}

Este artículo de investigación plantea que la violencia escolar o bullying es una problemática social que involucra distintos actores desde la prevención, tratamiento y sanciones a imponer, en caso de ser necesario. Así mismo, realiza un recorrido sobre las diversas responsabilidades como la moral, la jurídica y la civil. La primera, como aquella que se presenta al momento de violar o infringir las normas morales o religiosas y cuyo resultado no se exterioriza, mientras que la responsabilidad jurídica sucede cuando, a causa de una acción u omisión, se genera un perjuicio a otra persona o cuando el resultado de esos hechos es contrario al orden social. La responsabilidad civil concierne a las instituciones educativas, y específicamente en los rectores como representantes legales de esas personas jurídicas. Se concluye que corresponde en la escuela al docente o profesor y a los otros profesionales que día a día están en contacto con los niños, niñas y adolescente, un rol activo en la detección temprana, la prevención y la puesta en marcha de mecanismos de intervención ante la violencia escolar, sin olvidar la responsabilidad de las instituciones gubernamentales, que marcan las directrices encaminadas a formar seres humanos integrales, con valores y principios éticos y morales

\section{Palabras clave}

Bullyng, responsabilidad social, responsabilidad civil, comunidad educativa, responsabilidad penal, derechos humanos.

Recibido 12/11/2019*Aceptado 27/11/2019. 


\section{Introducción}

El bullying es, sin lugar a dudas, una vulneración de derechos, y en el país ha adquirido una mayor relevancia durante los últimos años debido a las denuncias de algunas víctimas, que han decidido contar su historia. Tal situación ha llamado la atención de colegios, del Estado y medios de comunicación. Es tanta la preocupación del Estado, que el Gobierno nacional expidió la Ley 1620 del 15 de marzo de 2013 "Por la cual se crea el sistema nacional de convivencia escolar y formación para el ejercicio de los derechos humanos, la educación para la sexualidad y la prevención y mitigación de la violencia escolar".

Dispone el artículo $3^{\circ}$ de dicha ley lo siguiente:

[...] Créase el sistema nacional de convivencia escolar y formación para los derechos humanos, la educación para la sexualidad y la prevención y mitigación de la violencia escolar, cuyos objetivos serán cumplidos a través de la promoción, orientación y coordinación de estrategias, programas y actividades, en el marco de la corresponsabilidad de los individuos, las instituciones educativas, la familia, la sociedad y el Estado. Este sistema reconoce a los niños, niñas y adolescentes como sujetos de derechos, y a la comunidad educativa en los niveles de preescolar, básica y media como la responsable de formar para el ejercicio de los mismos, conforme a lo dispuesto en la Constitución Política Nacional, las Leyes 115 de 1994 y 1098 de 2006, las disposiciones del Consejo Nacional de Política Social y demás normas asociadas a violencia escolar, que plantean demandas específicas al sistema escolar.

Este artículo es claro al señalar que es la comunidad educativa en los niveles de preescolar, básica y media responsable de formar para el ejercicio de los derechos de niños, niñas y adolescentes. Ahora bien, al pretender desentrañar el tipo de responsabilidad que cabe a las instituciones educativas en la prevención, confrontación y tratamiento del bullying, se deben tener en cuenta los aspectos que dan origen al reconocimiento de la responsabilidad por parte de estas instituciones, por lo que es necesario ubicarse en la acepción etimológica del término responsabilidad, la cual puede entenderse en dos sentidos:

1) Como la obligación que tiene una persona con respecto a otra persona o de una persona con respecto a una cosa, o 
2) Como la obligación que tiene una persona de resarcir a otra por causarle un daño o un perjuicio causado a otra o una pérdida sufrida por otra persona.

En cualquiera de los dos escenarios que se emplee, cuando se habla de responsabilidad siempre se va a entender implícita una relación bilateral cuyas obligaciones se encuentran previamente acordadas entre los sujetos, o que simplemente no se acordaron y la ley ha regulado ese tipo de resarcimientos, y, surge por ley, la obligación de reparar.

Bajo este entendido, se tiene entonces que la responsabilidad puede ser moral o jurídica. La responsabilidad moral es aquella que se presenta al momento de violar o infringir las normas morales o religiosas y cuyo resultado no se exterioriza, es decir, que es interno, es un asunto de la conciencia del individuo, que no genera consecuencias de índole jurídica por no afectar la vida en sociedad, ni dañar concretamente el patrimonio de otra persona (Irisarri, 2000, p.12).

Arturo Alessandri (1985, p.10), sobre lo anterior, conceptúa:

La responsabilidad moral es la que proviene de infringir los mandatos de la moral o de la religión. Es moralmente responsable el que ejecuta un hecho o incurre en una omisión contraria a la moral o a su religión [...] La responsabilidad moral suscita un mero problema de conciencia, que se plantea en el fuero interno del individuo y como las acciones y omisiones que la generan no causan daño a la persona o propiedad del otro, ni perturban el orden social, quedan fuera del dominio del derecho, que solo regula actos humanos que se exteriorizan.

Para los hermanos Mazeaud,

La responsabilidad moral es una noción puramente subjetiva; para saber si una persona es moralmente responsable, hay que examinar su estado espiritual [...] Desde el instante en que la conciencia de un individuo reprueba su actitud, es moralmente responsable, poco importa el resultado: un perjuicio no constituye un requisito necesario de la responsabilidad moral (Mazeaud, 1960, p. 7). 
Por su parte, el autor colombiano Gilberto Martínez Rave entiende por responsabilidad moral como

[...] aquella donde los resultados que deben enfrentarse son de índole moral, subjetivista, interno y no trascienden al campo externo de la persona y que surge generalmente cuando se violentan normas de conducta netamente morales, espirituales (Martínez Rave, G. 1988, p. 11).

Mientras, la responsabilidad jurídica sucede cuando, a causa de una acción u omisión, se genera un perjuicio a otra persona o cuando el resultado de esos hechos es contrario al orden social. En esta, al contrario de la responsabilidad moral, el resultado que debe ser siempre un perjuicio, transciende al campo externo, afectando la vida en sociedad y violando normas jurídicas, por lo cual sus efectos se escapan del fuero interno del individuo y pasan al mundo jurídico generando una carga en cabeza del autor del daño que puede consistir en una sanción o una reparación (Irisarri, 2000, pp. 13 - 14).

Para Alessandri la responsabilidad jurídica "es la que proviene de un hecho o una omisión que causa daño a otro o que la ley pena por ser contrario al orden social”" (Alessandri, 1981, p. 26).

Por su parte Martínez Rave, señala que la responsabilidad jurídica

[...] transciende al campo externo del sujeto. Afecta su vida de relación, su vida referida al grupo en el cual actúa y por lo tanto tiene repercusiones jurídicas. Esta responsabilidad es la que regula las normas que garantizan el desenvolvimiento de las relaciones jurídicas, o pautas de los componentes de la sociedad (Martínez, 1988, p. 12).

La responsabilidad jurídica se puede clasificar, a su turno, en dos grandes grupos: la responsabilidad civil y la responsabilidad penal.

En este mismo sentido, podemos concluir que la rotunda diferencia entre la responsabilidad civil y la responsabilidad penal, es que la primera tiene como finalidad el resarcir daños o perjuicios causados por la acción u omisión de un sujeto a través de una indemnización, mientras que la segunda responsabilidad tiene una función preventiva y condenatoria de la ejecución de conductas que se encuentran expresamente catalogadas como sancionadas en el ordenamiento juridico penal. 


\section{Responsabilidad civil de la escuela frente al bullying}

En la Constitución Politica de 1991, Colombia fue proclamado como un Estado social de derecho,

[...] organizado en forma de República unitaria, descentralizada, con autonomía de sus entidades territoriales, democrática, participativa y pluralista, fundada en el respeto de la dignidad humana, en el trabajo y la solidaridad de las personas que la integran y en la prevalencia del interés general. (Artículo1º, Constitución Nacional).

La Corte Constitucional define el Estado Social de Derecho de la siguiente manera:

a. La incidencia del Estado social de derecho en la organización sociopolítica puede ser descrita esquemáticamente desde dos puntos de vista: cuantitativo y cualitativo. Lo primero suele tratarse bajo el tema del Estado bienestar, y lo segundo bajo el tema de Estado constitucional democrático. La delimitación entre ambos conceptos no es tajante, cada uno de ellos hace alusión a su aspecto específico de un mismo asunto. Su complementariedad es evidente.

b. El Estado constitucional democrático ha sido la respuesta jurídico-política derivada de la actividad intervencionista del Estado. Dicha respuesta está fundada en nuevos valores derechos consagrados por la segunda y tercera generación de derechos humanos y se manifiesta institucionalmente a través de la creación de mecanismos de democracia participativa, de control político y jurídico en el ejercicio del poder y, sobre todo, a través de la consagración de un catálogo de principios y de derechos fundamentales que inspiran toda la interpretación y el funcionamiento de la organización política (Corte Constitucional, sentencia T - 406 de junio 5 de 1992).

En Colombia, el fundamento de la responsabilidad civil es de corte contractualista, y así quedó establecido en el preámbulo de la Constitución Política de 1991, cuando expresa en su Preámbulo:

[...] el pueblo de Colombia, en ejercicio de su poder soberano [...] y con la finalidad de garantizar a todos sus integrantes la vida, la convivencia, el trabajo, la justicia, la igualdad, el conocimiento, la libertad y la paz, dentro de un marco jurídico, democrático y participativo que garantice un orden político, económico y social justo, [...] decreta, sanciona y promulga la Constitución Política de 1991. 
Como proyecto constitucional a seguir para el desarrollo y el avance de las condiciones sociales de todos los ciudadanos, legitimando al Estado para que garantizara esos principios fundantes o estructurales, de aquí parte el compromiso que el Estado tiene de lograr la institucionalización, la cual consiste, por una parte, en la conformación de un aparato administrativo, es decir, de un cuerpo de funcionarios que actúan a nombre del Estado de modo especializado y permanente. La institucionalización también se expresó en la imposición de un conjunto de normas para regular la vida social de tal modo que quedara suprimida la facultad de cada uno de hacer justicia por su propia mano. Operó así la racionalización de la fuerza, pues esta quedó bajo el monopolio del Estado y como último recurso.

De esta manera se construyó un derecho oficial, el cual determinó las condiciones bajo las cuales se ejercía la coacción de manera autorizada y la aprobación de los individuos que podían hacerlo. Esta es una forma de institucionalización o de protección a los individuos. Cuando esta protección alcanzó cierto grado, se pudo hablar de la existencia de seguridad colectiva y con esta se aspiraba la pacificación como proyecto público continuo.

Por otro lado, se tiene que la Ley General de Educación, del 115 de febrero 8 de 1994, en el artículo $5^{\circ}$, señala los fines de la educación y particularmente en el inciso $2^{\circ}$ de dicho artículo, plantea que uno de esos fines es "la formación en el respeto a la vida y a los demás derechos humanos, a la paz, a los principios democráticos, de convivencia, pluralismo, justicia, solidaridad y equidad, así como el ejercicio de la tolerancia y de la libertad". Se evidencia así la gran responsabilidad que, desde los centros educativos, debe ser tenida en cuenta para formar ciudadanos desde la primera edad escolar, comprometidos con la equidad, la convivencia, la solidaridad, los valores, la democracia, la resolución pacífica de conflictos, el respeto de los derechos de los demás y que dispongan de ellos para el beneficio de toda una colectividad. Las escuelas deben ser, pues, espacios adecuados para el aprendizaje de la convivencia en el marco de una democracia.

Para el tema en estudio, en lo que se refiere al matoneo o bullying en las instituciones educativas, se puede afirmar que la responsabilidad que prospera es la responsabilidad civil, 
teniendo en cuenta lo prescrito en el artículo 2347 de Código Civil colombiano ${ }^{1}$, y es precisamente lo que concierne al hecho de los que estuvieren a su cuidado dónde se afianza esta responsabilidad en las instituciones educativas, y específicamente en los rectores como representantes legales de esas personas jurídicas.

Así las cosas, se encuentran como elementos para que se dá este tipo de responsabilidad:

1) Un vínculo de jerarquía, tal como se da entre docente y discente, coordinador académico y rector.

2) Que las personas responsables, llámese rector o llámese docente, responden por la diligencia en la atención de los discentes, es decir, que en caso de responsabilidad solo pueden exonerarse de responder en la medida en que demuestren su diligencia en el caso concreto. No olvidemos que la responsabilidad civil, llamada por el hecho ajeno, es de carácter objetivo y no subjetivo, por tanto, es de medios y no de resultados.

En este sentido, a través de la ley 60 de 1993, en el artículo segundo, se delegó en los municipios que las secretarías de educación ejercieran la inspección, vigilancia, supervisión y evaluación de los servicios y, por esta medida, que en los casos de irregularidades en la prestación del servicio educativo en los niveles de preescolar, básica y media, son las Secretarías de Educación de los municipios las competentes para adelantar cualquier actuación que conlleven en el ejercicio de sus funciones, sin discriminar que la institución sea de carácter oficial o privado.

La complejidad del sistema, tanto en lo que se refiere a los hechos objetos de la regulación, como a la regulación misma, hace infructuosa la pretensión racionalista que consiste en prever todos los conflictos sociales posibles para luego asignar a cada uno de ellos la solución normativa correspondiente. Es así como en el Sistema jurídico del Estado Social de Derecho se acentúa de manera dramática — problema planteado por Aristóteles — de la necesidad de adaptar, corregir y acondicionar la aplicación de la norma por medio de la intervención del juez. Pero esta intervención no se manifiesta solo por el mecanismo necesario para solucionar

\footnotetext{
${ }^{1}$ Ver Artículo 2347 del Código civil colombiano: Responsabilidad por el hecho propio y de las personas a cargo. Toda persona es responsable, no solo de sus propias acciones para el efecto de indemnizar el daño sino del hecho de aquellos que estuvieren a su cuidado.

Así, los directores de colegios y escuelas responden del hecho de los discípulos mientras están bajo su cuidado.
} 
una disfunción, sino, también, y sobre todo, como un elemento indispensable para mejorar las condiciones de comunicación entre el derecho y la sociedad, es decir, para favorecer el logro del valor justicia, así ello conlleve un detrimento de la seguridad jurídica (Molina, 2007, p. 239). Por tanto, desde antes de que se promulgara la Ley 1620 de 2013, ya existía la obligación de proteger y prevenir la violencia escolar.

Para cerrar entonces en lo que respecta a la responsabilidad subjetiva y objetiva, es pertinente presentar la consagración de los conceptos, de manera tal que la responsabilidad civil subjetiva tiene como fundamento el análisis de la conducta del sujeto, que en sus comienzos estuvo dominada por un criterio sicológico pues este juicio, aplicado al derecho, parte del supuesto de la existencia de un estado anímico reprochable en un sujeto de derecho por su obrar antijurídico, en perjuicio de otro sujeto que provoca la reacción del ordenamiento jurídico para la defensa del derecho ofendido (Santos, 2011, p. 24). En este sentido, Chironi afirma que se trata de la parte subjetiva de la injuria, por cuanto la culpa, "como defecto imputable de la diligencia impuesta al agente, determina la violación con efecto jurídico, del derecho ajeno, siendo la razón principal por el cual el hecho ilícito es hecho jurídico" (Chironi, 1978, p. 41).

\section{Antecedentes jurídicos}

Al hablar de la responsabilidad contractual, se hace alusión a la obligación de reparar los perjuicios provenientes del incumplimiento, o del retraso en el cumplimiento, o del cumplimiento defectuoso de una obligación pactada en un contrato. Para que exista esta clase de responsabilidad es necesario que haya una relación anterior entre el autor del daño y quien lo sufre y que el perjuicio sea causado con ocasión de esa relación. Dentro del estudio de este tema se pueden observar claramente dos grupos de teorías bien definidas: por una parte, aquellas que presentan la responsabilidad contractual cuando se ha incumplido una obligación proveniente de un contrato anteriormente celebrado; otras teorías sostienen que se está en presencia de responsabilidad contractual cuando se ha incumplido una obligación emanada no solamente de un contrato, sino cuando se incumple una obligación derivada de vínculo jurídico anterior o de la ley (Irisarri, 2000. pp. 17 - 18). 
Ampliando lo que se ha dispuesto anteriormente, se tiene en cuenta la posición de Alberto Tamayo Lombana, al establecer las situaciones que versan sobre las dos grandes ramas de la responsabilidad civil, la contractual y la extracontractual. Para lo que respecta a la primera, señala:

La Responsabilidad Civil Contractual, resulta de la inejecución parcial o total, o de la ejecución imperfecta o tardía de una obligación estipulada en un contrato válido. Presupone por lo tanto la existencia de un contrato celebrado entre las partes y el incumplimiento o cumplimiento imperfecto de alguna de las obligaciones estipuladas en él. Serían ejemplos: un vendedor no transfiere la cosa vendida, como se lo impone el artículo 1849 del Código Civil; o lo hace tardíamente, o la cosa es de inferior calidad o se encuentra averiada. Un transportador no transporta las mercaderías que se le han entregado para tal fin, o las transporta pero las entrega en mal estado, quebrantando las obligaciones que le imponen el contrato y el artículo 982 del Código de Comercio (Tamayo, 2005, p. 28).

Con respecto a la segunda, señala:

La extracontractual o delictual (delictual propiamente dicha y cuasidelictual), se da en ausencia de un contrato. Resulta de un hecho cualquiera: un automovilista arrolla a un peatón. El accidente pudo haber ocurrido por imprudencia, pero de todas maneras sin intención de ocasionar el daño (responsabilidad cuasidelictual). Otra hipótesis: el peatón era enemigo del automovilista y este lo lesionó a propósito, intencionalmente (responsabilidad delictual). En cualquiera de los dos casos se ha quebrantado la regla moral y de justicia social elemental de no perjudicar a otro y, en consecuencia, el autor del daño debe repararlo (Voirin, p. 1984).

A partir de esta responsabiliad civil contractual que se genera con ocasión de la celebración del contrato de formación suscrito entre los padres de familia y las instituciones de educación básica, media y secundaria, materializado en lo que genéricamente se denomina matrícula, se generan para las partes obligaciones bilaterales siendo asunto de este capítulo el cuidado integral a tener con los niños, niñas y adolescentes, por lo que se afirma que ese bien jurídico protegido desde la Constitución Política, no se protege a partir de la Ley 1620 de 2013, sino como veremos a continuación Acerca de ello, el bullying ha sido un tema de preocupación y protección jurídica, inicialmente a través de jurisprudencia y hoy día a través de dicha Ley. 
En este escenario, se afirma que la protección que se debe a los niños, niñas y adolescentes no es un aspecto que se haya visibilizado a partir del 2013, sino que tiene antecedentes entrañados en los derechos fundametales reconocidos en la Constitución Política tal como se establece, por ejemplo en los siguientes artículos: el 67 de la Constitución Política, define la educación como:

[...] un derecho de la persona y un servicio público que tiene una función social; la educación es un derecho de la persona y un servicio público que tiene una función social; con ella se busca el acceso al conocimiento, a la ciencia, a la técnica, y a los demás bienes y valores de la cultura. La educación formará al colombiano en el respeto a los derechos humanos, a la paz y a la democracia; y en la práctica del trabajo y la recreación, para el mejoramiento cultural, científico, tecnológico y para la protección del ambiente. El Estado, la sociedad y la familia son responsables de la educación, que será obligatoria entre los cinco y los quince años de edad y que comprenderá como mínimo, un año de preescolar y nueve de educación básica. La educación será gratuita en las instituciones del Estado, sin perjuicio del cobro de derechos académicos a quienes puedan sufragarlos. Corresponde al Estado regular y ejercer la suprema inspección y vigilancia de la educación con el fin de velar por su calidad, por el cumplimiento de sus fines y por la mejor formación moral, intelectual y física de los educandos; garantizar el adecuado cubrimiento del servicio y asegurar a los menores las condiciones necesarias para su acceso y permanencia en el sistema educativo. La Nación y las entidades territoriales participarán en la dirección, financiación y administración de los servicios educativos estatales, en los términos que señalen la Constitución y la ley.

El artículo 44 del mismo ordenamiento preceptúa:

Son derechos fundamentales de los niños: la vida, la integridad física, la salud y la seguridad social, la alimentación equilibrada, su nombre y nacionalidad, tener una familia y no ser separados de ella, el cuidado y amor, la educación y la cultura, la recreación y la libre expresión de su opinión. Serán protegidos contra toda forma de abandono, violencia física o moral, secuestro, venta, abuso sexual, explotación laboral o económica y trabajos riesgosos. Gozarán también de los demás derechos consagrados en la Constitución, en las leyes y en los tratados internacionales ratificados por Colombia. La familia, la sociedad y el Estado tienen la obligación de asistir y proteger al niño para garantizar su desarrollo armónico e integral y el ejercicio pleno de sus derechos. Cualquier persona puede exigir de la autoridad competente su cumplimiento y la sanción de los infractores. Los derechos de los niños prevalecen sobre los derechos de los demás. 
El artículo 45 de la Constitución también dispone:

El adolescente tiene derecho a la protección y a la formación integral. El Estado y la sociedad garantizan la participación activa de los jóvenes en los organismos públicos y privados que tengan a cargo la protección, educación y progreso de la juventud.

En el mismo tenor, el Código de la Infancia y Adolescencia, establece en los artículos 39, 40 y 41, las obligaciones de la familia, la sociedad y el Estado. En ellos se enumeran, sin llevar a entender que son los únicos o que se trata de una relación taxativa, cuáles son las obligaciones de cada uno de estos estamentos frente a la formación y protección que se debe a los niños, niñas y adolescentes, resaltando principalmente los contenidos en los siguientes numerales según cada artículo así:

Obligaciones de la familia [...] Son obligaciones de la familia para garantizar los derechos de los niños, las niñas y los adolescentes:

1. Protegerles contra cualquier acto que amenace o vulnere su vida, su dignidad y su integridad personal [...]

Obligaciones de la sociedad. En cumplimiento de los principios de corresponsabilidad y solidaridad, las organizaciones de la sociedad civil, las asociaciones, las empresas, el comercio organizado, los gremios económicos y demás personas jurídicas, así como las personas naturales, tienen la obligación y la responsabilidad de tomar parte activa en el logro de la vigencia efectiva de los derechos y garantías de los niños, las niñas y los adolescentes. En este sentido, deberán:

2. Responder con acciones que procuren la protección inmediata ante situaciones que amenacen o menoscaben estos derechos [...]

3. Dar aviso o denunciar por cualquier medio, los delitos o las acciones que los vulneren o amenacen $[\ldots]$ 
Obligaciones del Estado. El Estado es el contexto institucional en el desarrollo integral de los niños, las niñas y los adolescentes. En cumplimiento de sus funciones en los niveles nacional, departamental, distrital y municipal deberá:

1. Garantizar el ejercicio de todos los derechos de los niños, las niñas y los adolescentes $[\ldots]$

4. Asegurar la protección y el efectivo restablecimiento de los derechos que han sido vulnerados [...]

5. Promover la convivencia pacífica en el orden familiar y social.

6. Investigar y sancionar severamente los delitos en los cuales los niños, las niñas y las adolescentes son víctimas, y garantizar la reparación del daño y el restablecimiento de sus derechos vulnerados [...]

7. Promover en todos los estamentos de la sociedad, el respeto a la integridad física, psíquica e intelectual y el ejercicio de los derechos de los niños, las niñas y los adolescentes y la forma de hacerlos efectivos [...]

8. Formar a los niños, las niñas y los adolescentes y a las familias en la cultura del respeto a la dignidad, el reconocimiento de los derechos de los demás, la convivencia democrática y los valores humanos y en la solución pacífica de los conflictos [...] 16. Prevenir y atender en forma prevalente, las diferentes formas de violencia y todo tipo de accidentes que atenten contra el derecho a la vida y la calidad de vida de los niños, las niñas y los adolescentes.

19. Garantizar un ambiente escolar respetuoso de la dignidad y los Derechos Humanos de los niños, las niñas y los adolescentes y desarrollar programas de formación de maestros para la promoción del buen trato.

20. Erradicar del sistema educativo las prácticas pedagógicas discriminatorias o excluyentes y las sanciones que conlleven maltrato, o menoscabo de la dignidad o integridad física, psicológica o moral de los niños, las niñas y los adolescentes [...]

27. Prestar especial atención a los niños, las niñas y los adolescentes que se encuentren en situación de riesgo, vulneración o emergencia. 


\section{Obligación ética fundamental de los establecimientos educativos}

La ley 1098 de 2006 o Código de infancia y adolescencia, dispone en el artículo 43, referido a la obligación ética fundamental de los establecimientos educativos, que "las instituciones de educación primaria y secundaria, públicas y privadas, tendrán la obligación fundamental de garantizar a los niños, niñas y adolescentes el pleno respeto a su dignidad, vida, integridad física y moral dentro de la convivencia escolar”, y, para tal efecto, señala el artículo en los numerales 2 y 3 que deberán:

$[\ldots]$

1. Formar a los niños, niñas y adolescentes en el respeto por los valores fundamentales de la dignidad humana, los Derechos Humanos, la aceptación, la tolerancia hacia las diferencias entre personas. Para ello deberán inculcar un trato respetuoso y considerado hacia los demás, especialmente hacia quienes presentan discapacidades, especial vulnerabilidad o capacidades sobresalientes.

2. Proteger eficazmente a los niños, niñas y adolescentes contra toda forma de maltrato, agresión física o sicológica, humillación, discriminación o burla de parte de los demás compañeros y de los profesores.

3. Establecer en sus reglamentos los mecanismos adecuados de carácter disuasivo, correctivo y reeducativo para impedir la agresión física o psicológica, los comportamientos de burla, desprecio y humillación hacia niños y adolescentes con dificultades en el aprendizaje, en el lenguaje o hacia niños y adolescentes con capacidades sobresalientes o especiales.

\section{Obligaciones complementarias de las instituciones educativas. Los directivos y} docentes de los establecimientos académicos y la comunidad educativa en general pondrán en marcha mecanismos para:

$[\ldots]$

4. Garantizar a los niños, niñas y adolescentes el pleno respeto a su dignidad, vida, integridad física y moral dentro de la convivencia escolar.

5. Proteger eficazmente a los niños, niñas y adolescentes contra toda forma de maltrato, agresión física o psicológica, humillación, discriminación o burla de parte de los demás compañeros o profesores.

6. Establecer en sus reglamentos los mecanismos adecuados de carácter disuasivo, correctivo y reeducativo para impedir la agresión física o psicológica, los comportamientos de burla, desprecio y humillación hacia los niños, niñas y adolescentes con dificultades de aprendizaje, en el lenguaje o hacia niños o adolescentes con capacidades sobresalientes o especiales. 
De la interpretación armónica de los anteriores artículos, se evidencia que para el Estado colombiano ha sido, a partir la Constitución de 1991, una prioridad la protección de los derechos de los niños, niñas y adolescentes, ya que a partir de este estatuto normativo prevalece la dignidad del ser humano, y es en ese sentido que el Estado ha propendido por generar desde sus diferentes actores acciones encaminadas a satisfacer de manera puntual controversias que se tornan colectivas que obligatoriamente deben ser afrontadas en el sentido de modificar o cambiar comportamientos de los individuos inmersos en la sociedad. Se comparte la postura de Morales Ortega cuando afirma que

[...] la violencia y la victimización o acoso escolar podría ser el resultado o la manifestación del desconocimiento de los derechos de los niños y adolescentes en los centros educativos, ya sea por acción o por inacción u omisión. En este orden de ideas, se puede afirmar que el acoso en la escuela es un problema serio, y cuando un plantel educativo no llega a responder a éste, puede decirse que esa escuela no está cumpliendo con sus objetivos, pues ella como institución que forma, está llamada a dar respuesta también a este tipo de situación. Es deber de la escuela fomentar las acciones que permitan ir de una cultura de violencia a una cultura de paz con visión preventiva, que promueva los derechos y las responsabilidades compartidas para la convivencia social en general y la convivencia escolar en particular (Morales, 2013, p. 60).

Un hecho que comienza como un hostigamiento en medio de las clases, a la hora del recreo, a la salida de la escuela, puede terminar convirtiéndose, en una verdadera tortura que puede tener graves consecuencias para el que la sufre, incluso influir en el rendimiento académico y en la deserción escolar, de ahí la importancia que las autoridades académicas se involucren en la problemática

La educación es un derecho humano, un servicio público y garantizar el acceso a ella sin violencia es responsabilidad del Estado y por extensión también responsabilidad de sus funcionarios -incluidos maestros y autoridades escolares- éstos, tienen el deber de investigar sin demora los casos de abusos, "imponer las sanciones adecuadas a quienes los realizan, respaldar y ayudar a las víctimas de violencia para que superen sus secuelas físicas y emocionales, y lo más importante tomar medidas para prevenir la ocurrencia de esos abusos" 
En este sentido, Morales Ortega (2013, p. 57) manifiesta:

\begin{abstract}
Esta nueva visión del niño, fundamentada en el interés superior del mismo, significa que la atención de la niñez debe centrase en la implementación de políticas públicas que permitan el desarrollo integral y garanticen su bienestar. Exige igualmente la necesidad de cambios en las prácticas sociales en las que interactúan los adultos y menores.
\end{abstract}

Así mismo, se constata que, la preocupación no es solamente a nivel nacional, pues desde las instancias internacionales se ha realizado todo un desarrollo normativo para proteger los derechos de los más vulnerables de la sociedad y, en el caso particular de los niños, niñas y adolescentes, la creación de políticas públicas encaminadas a prevenir y proteger contra este tipo de violencia, también a afrontar, e incluso prohibir la práctica de conductas que permitan el maltrato físico o mental, descuido o tratos omisivos, abuso o explotación sexual.

Tal es el caso de la Convención sobre los Derechos del Niño — adoptada por la Asamblea General de las Naciones Unidas el 20 de noviembre de 1989- para lo cual se le traslada a los Estados miembros de la Convención la obligatoriedad de realizar no solo las políticas públicas acordes sino hacer las actividades de gestión pública encaminadas a su realización. A este respecto, en la escuela cada educador debe velar por los derechos de los niños, niñas y adolescentes pues la protección integral de éstos es responsabilidad de todos, según lo dispone la mencionada Convención.

En Colombia, la ruta de atención de este tipo de violencia una vez se ha realizada ha sido marcada por la ley de la siguiente manera: 


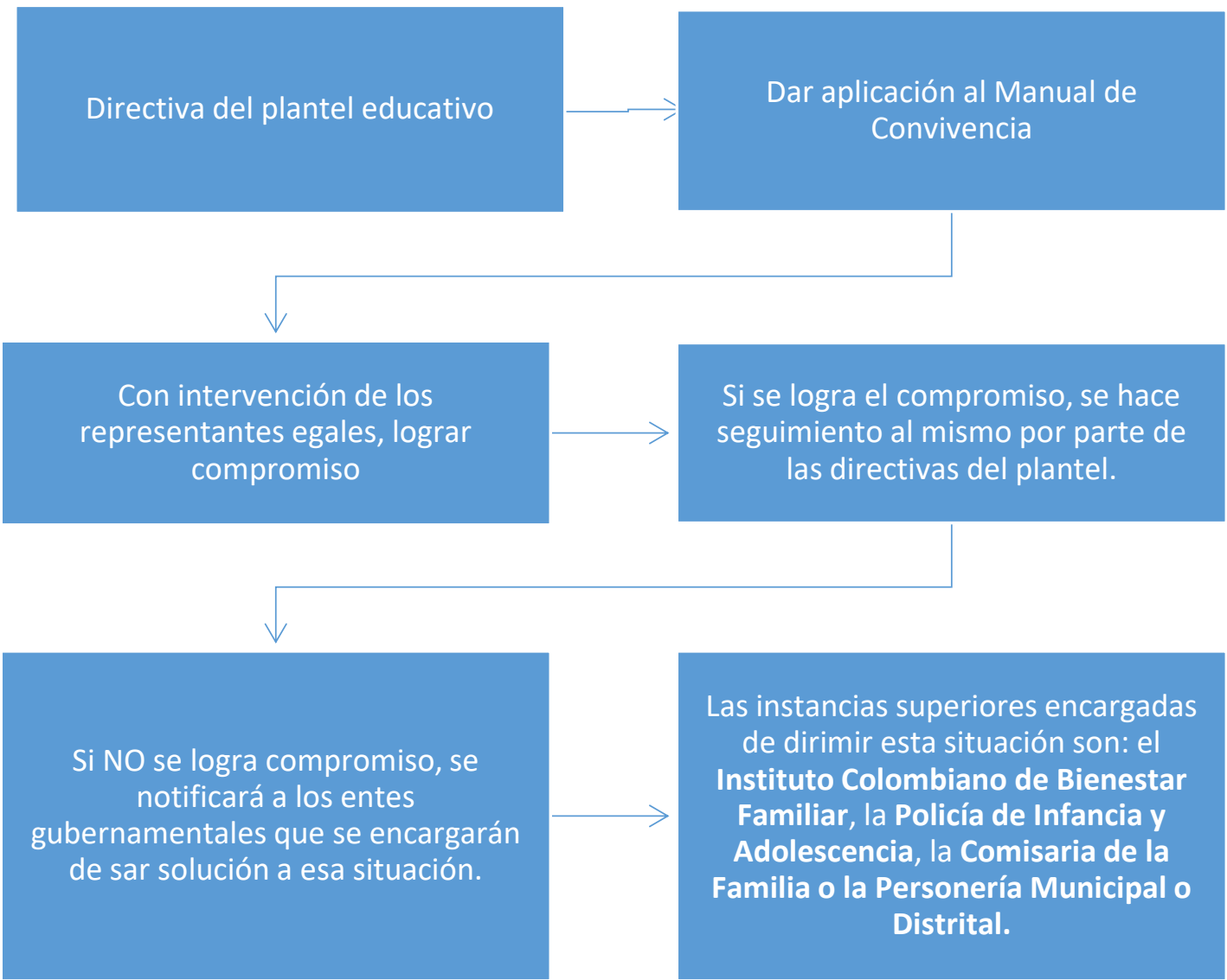

Sobre el tema se debe indicar también que el artículo 17 de la Ley 1620 de 2013 ya mencionada, dispone sobre la responsabilidad de los establecimientos educativos que éstos tendrán además de las que establece la normatividad vigente y que le son propias, las siguientes responsabilidades:

$[\ldots]$

1) Garantizar a sus estudiantes, educadores, directivos docentes y demás personal de los establecimientos escolares el respeto a la dignidad e integridad física y moral en el marco de la convivencia escolar, los derechos humanos, sexuales y reproductivos.

2) Implementar el comité de escolar de convivencia y garantizar el cumplimiento de sus funciones acorde con lo estipulado en los artículos 11,12 y 13 de la presente Ley.

3) Desarrollar los componentes de prevención, promoción y protección a través del manual de convivencia, y la aplicación de la Ruta de Atención Integral para la Convivencia Escolar, con el fin de proteger a los estudiantes contra toda forma de acoso, 
violencia escolar y vulneración de los derechos humanos sexuales y reproductivos, por parte de los demás compañeros, profesores o directivos docentes.

4) Revisar y ajustar el proyecto educativo institucional, el manual de convivencia, y el sistema institucional de evaluación de estudiantes anualmente, en un proceso participativo que involucre a los estudiantes y en general a la comunidad educativa, a la luz de los enfoques de derechos, de competencias y diferencial, acorde con la Ley General de Educación, la Ley 1098 de 2006 y las normas que las desarrollan.

5) Revisar anualmente las condiciones de convivencia escolar del establecimiento educativo e identificar factores de riesgo y factores protectores que incidan en la convivencia escolar, protección de derechos humanos, sexuales y reproductivos, en los procesos de autoevaluación institucional o de certificación de calidad, con base en la implementación de la Ruta de Atención Integral y en las decisiones que adopte el comité escolar de convivencia.

6) Emprender acciones que involucren a toda la comunidad educativa en un proceso de reflexión pedagógica sobre los factores asociados a la violencia y el acoso escolar y la vulneración de los derechos sexuales y reproductivos y el impacto de los mismos incorporando conocimiento pertinente acerca del cuidado del propio cuerpo y de las relaciones con los demás, inculcando la tolerancia y el respeto mutuo.

7) Desarrollar estrategias e instrumentos destinados a promover la convivencia escolar a partir de evaluaciones y seguimiento de las formas de acoso y violencia escolar más frecuentes.

8) Adoptar estrategias para estimular actitudes entre los miembros de la comunidad educativa que promuevan y fortalezcan la convivencia escolar, la mediación y reconciliación y la divulgación de estas experiencias exitosas.

9) Generar estrategias pedagógicas para articular procesos de formación entre las distintas áreas de estudio.

\section{Conclusión}

El tema de la violencia escolar o bullying es una problemática social que involucra distintos actores desde la prevención, tratamiento y sanciones a imponer, en caso de ser necesario. Lo cierto es que actualmente es una de las causas más frecuentes en la deserción estudiantil, junto con el consumo de drogas en niños, niñas y adolescentes, población estudiantil con problemas psicológicos que, de no ser atendidos de manera adecuada, desencadenará una sociedad proclive a resolver sus controversias con la violencia e implementando la ley del más fuerte.

Corresponde en la escuela al docente o profesor y a los otros profesionales que día a día están en contacto con los niños, niñas y adolescente, un rol activo en la detección temprana, la prevención y la puesta en marcha de mecanismos de intervención ante la violencia 
escolar. Es un problema que no puede desconocerse, siendo necesario hacer consciencia y sensibilizarse frente a su ocurrencia, pero, sin lugar a dudas, es una responsabilidad compartida con la familia como célula básica de la sociedad, realizando una labor conjunta con las directivas de los colegios, el cuerpo docente y el grupo interdisciplinario que integra la comunidad académica. Todo ello, sin olvidar la responsabilidad que reposa en las instituciones gubernamentales, que marcan las directrices encaminadas a formar seres humanos integrales, con valores y principios éticos y morales, que propendan y ejerzan los derechos humanos, para lograr una convivencia pacífica, con actitud de tolerancia e inclusión, conceptos claves en estos tiempos de postconflicto.

Realmente el Estado ideal es aquel donde el hombre sea capaz de autorregularse, y en el que, sin que existan normas coercitivas, pueda lograr una convivencia pacífica, sin que no se determinen sanciones por el cumplimiento de una obligación o un deber, aunque, desafortunadamente, en Colombia la cultura es normativizar toda conducta para crear buenas prácticas.

En tal sentido, la Corte Constitucional, en sentencia C-371 del 25 de agosto de 1994, ha manifestado:

Derecho a la integridad personal. Los niños, las niñas y los adolescentes tienen derecho a ser protegidos contra todas las acciones o conductas que causen muerte, daño o sufrimiento físico, sexual o psicológico. En especial, tienen derecho a la protección contra el maltrato y los abusos de toda índole por parte de sus padres, de sus representantes legales, de las personas responsables de su cuidado y de los miembros de su grupo familiar, escolar y comunitario.

Así, mismo la Corte Constitucional de Colombia ha señalado que para reprender al niño no es necesario causarle daño en su cuerpo o en su alma. Es suficiente muchas veces asumir frente a él una actitud severa despojada de violencia, para lo cual, sea necesario reconvenirlo con prudente energía; privarlo temporalmente de cierta diversión; abstenerse de otorgarle determinado premio o distinción; hacerle ver los efectos negativos de la falta cometida. 


\section{Referencias}

Alessandri Rodríguez, A (1981). De la responsabilidad extracontractual en el Derecho Civil. Santiago de Chile: Imprenta Universal.

Calmaestra, J. et al (2016). Yo a eso no juego. Bullying y cyberbullying en la infancia. Save The Children España. Consultado en noviembre de 2016 Disponible en: https://www.savethechildren.es/sites/default/files/imce/docs/yo_a_eso_no_juego.pdf Chironi, G. P. (1978). La culpa en el Derecho Civil moderno. Madrid - España: Editorial REUS.

Diario el Espectador (12/11/ 2013). "Tres de cada cinco víctimas de "bullying" en Colombia piensan en suicidio. Disponible https://www.elespectador.com/noticias/nacional/tres-de-cada-cinco-víctimas-de-bullyingencolombia-pien-articulo-457937.

Irisarri Boada, C. (2000) El daño antijurídico y la responsabilidad extracontractual del Estado colombiano. Bogotá D. C.: Pontificia Universidad Javeriana. Tesis de grado,

Martínez Rave, G (1988). La responsabilidad civil extracontractual en Colombia. Medellín - Colombia: Editorial Dike, $4^{\mathrm{a}}$ Edición,

Mazeaud, Henry - L - J. (1960) Lecciones de Derecho Civil. Parte segunda, Vol. II. La Responsabilidad Civil. Los cuasicontratos. Buenos Aires - Argentina: Ediciones Jurídicas Europa - América.

Molina Betancur, C (2007). "El rol institucional de la Corte Constitucional". Revista de Derecho, Universidad del Norte, No. 28, Barranquilla, 2007. 
Morales Ortega, H (2013). "Violencia, victimización y Derecho en la escuela”. En Conflicto, violencia y mediación en los espacios educativos. Barranquilla, Colombia: Editorial Uniautónoma.

Revista Semana (2/1/2014) “El 'bullying' no es un juego de niños”. Disponible en: http://www.semana.com/vida-moderna/articulo/el-bullying-matoneo-no-es-un-juego-deninos/375864-3

República de Colombia. Constitución Política de 1991.

República de Colombia. Corte Constitucional de Colombia. Sentencia T - 406 de Junio 5 de 1992

República de Colombia. Código civil colombiano.

República de Colombia. Ley 60 de 1993.

República de Colombia. Código de la infancia y adolescencia.

República de Colombia. Corte Constitucional Sentencia C-371 del 25 de agosto de 1994.

Santos Ballesteros, J (2011) Responsabilidad profesional. Consejo Superior de la Judicatura

Sala Administrativa, Escuela Judicial Rodrigo Lara Bonilla, Colombia.

Tamayo Lombana, A (2005). La responsabilidad civil extracontractual y la contractual. Ediciones Doctrina y Ley, Colombia, 2005.

Voirin, P, actualizado por Gilles De Goubeaux (1984), en “Manuel de droit civil”, t. I: París: Librairie Générale de Droit et de Jurisprudence, 